\title{
Desempenho de novilhas leiteiras em pastagens anuais de inverno sob sistema de integração lavoura-pecuária
}

\author{
Hernani Alves da Silva(1), Aníbal de Moraes ${ }^{(1)}$, Paulo César de Faccio Carvalho(2) e Laíse da Silveira Pontes ${ }^{(3)}$ \\ (1)Universidade Federal do Paraná, Departamento de Fitotecnia e Fitossanitarismo, Setor de Ciências Agrárias, Rua dos Funcionários, \\ no 1.540, CEP 80035-050 Curitiba, PR. E-mail: hernani@castrolanda.coop.br, anibalm@ufpr.br (2)Universidade Federal do Rio Grande do \\ Sul, Departamento de Plantas Forrageiras e Agrometeorologia, Avenida Bento Gonçalves, oㅡ.712, Caixa Postal 776, CEP 91501-970 Porto \\ Alegre, RS. E-mail: paulocfc@ufrgs.br (3)Instituto Agronômico do Paraná, Avenida Euzébio de Queiróz, s/non, Uvaranas, Caixa Postal 129, \\ CEP 84001-970 Ponta Grossa, PR. E-mail: laisepontes@iapar.br
}

Resumo - O objetivo deste trabalho foi avaliar a viabilidade da recria de novilhas leiteiras em pastagens de inverno puras ou consorciadas, sob sistema de integração lavoura-pecuária. O experimento foi realizado no Município de Castro, PR. Utilizou-se o delineamento experimental de blocos ao acaso, em arranjo fatorial, com duas categorias de animais - leves, com $192 \pm 40,9 \mathrm{~kg}$, e pesados, com $278 \pm 41,2 \mathrm{~kg}$-, e dois tipos de pastagem: consorciada, composta de azevém anual (Lolium multiflorum), aveia-preta (Avena strigosa), trevo branco (Trifolium repens) e trevo vermelho (Trifolium pratense); e pastagem pura de azevém anual. Foi utilizado o método de pastoreio contínuo com lotação variável, com altura de manejo de $20 \mathrm{~cm}$. A pastagem com azevém anual proporcionou ganho de peso médio diário significativamente superior $(0,93 \pm 0,032 \mathrm{~kg}$ por dia por animal) ao da pastagem consorciada $(0,79 \pm 0,032 \mathrm{~kg}$ por dia por animal). Os animais leves apresentaram maior ganho de peso por hectare $\left(3,54 \pm 0,163 \mathrm{~kg} \mathrm{ha}^{-1}\right.$ por dia) do que os pesados $\left(2,99 \pm 0,163 \mathrm{~kg} \mathrm{ha}^{-1}\right.$ por dia), o que foi influenciado pelo tipo de pastagem: animais leves apresentaram melhor desempenho em pastagem pura, e animais pesados em pastagem consorciada. A recria de novilhas leiteiras é viável durante a fase de pastagens de sistemas de integração lavoura-pecuária.

Termos para indexação: desempenho animal, recria de novilhas, sistema integrado de produção.

\section{Dairy heifers' performance in winter annual pastures under integrated crop-livestock system}

\begin{abstract}
The objective of this work was to assess the rearing viability of dairy heifers grazing single or intercropped winter pastures, under crop-livestock integration system. The experiment was carried out in Castro, Paraná state, Brazil. A complete block design was used, in a factorial arrangement, with two animal categories - light-weight, with $192 \pm 40.9 \mathrm{~kg}$, and heavy-weight animals, with $278 \pm 41.2 \mathrm{~kg}$-, and two pasture types: annual ryegrass (Lolium multiflorum) intercropped with black oat (Avena strigosa), white clover (Trifolium repens) and red clover (Trifolium pratense); and single annual ryegrass pasture. A continuous grazing method with variable stocking was used, with $20-\mathrm{cm}$ sward management height. Single annual ryegrass pasture provided an average daily gain $(0.93 \pm 0.032 \mathrm{~kg}$ per day per animal) significantly higher than intercropped pastures $\left(0.79 \pm 0.032 \mathrm{~kg}\right.$ per day). Light animals had higher weight gain per hectare $\left(3.54 \pm 0.163 \mathrm{~kg} \mathrm{ha}^{-1}\right.$ per day) than heavy animals $\left(2.99 \pm 0.163 \mathrm{~kg} \mathrm{ha}^{-1}\right.$ per day), which was influenced by pasture type: light animals had best performance on single pasture, and heavy animals on intercropped pastures. Rearing dairy heifers is viable in the pasture phase of integrated crop-livestock systems.
\end{abstract}

Index terms: animal performance, heifer rearing, integrated production system.

\section{Introdução}

O sistema de criação de bezerras e novilhas leiteiras é um investimento de médio e longo prazo. Na formação do custo de produção do leite, o custo da criação dos animais de reposição é considerado uma das maiores fontes de despesas (15 a 20\%), abaixo somente das despesas com a alimentação do rebanho em produção (Heinrichs, 1993). Segundo Gabler et al. (2000), a alimentação representa $60 \%$ do custo total da criação de novilhas de reposição. Portanto, minimizar gastos na criação de novilhas sem prejudicar o potencial produtivo destes animais deve ser priorizado nos sistemas de criação. 
Na região Sul do Brasil, o uso de pastagens de inverno intercaladas com culturas comercias no verão, como soja, milho ou feijão, constitui uma estratégia de elevada importância em virtude da carência de alternativas de cultivos agrícolas economicamente viáveis durante o inverno (Balbinot Junior et al., 2009). Assim, sistemas de integração lavoura-pecuária (ILP) possibilitam a intensificação da viabilidade econômica de áreas agrícolas subutilizadas e proporcionam vantagens biológicas aos sistemas de produção (Balbinot Junior et al., 2009), sendo uma boa oportunidade de negócio, com a possibilidade de recria de novilhas durante o inverno. Contudo, para que esses sistemas expressem todo o seu potencial, algumas práticas devem ser consideradas, como rotação de culturas, plantio direto, correção da acidez e da fertilidade do solo, emprego de genótipos melhorados e manejo correto da pastagem, com carga animal adequada (Moraes et al., 2002).

Smith et al. (2008) relatam que a crescente diversidade de espécies nos sistemas de produção pode levar a aumentos significativos na produção das culturas, especificamente na do milho. Sleugh et al. (2000) sugerem que o maior nível de proteína bruta, em pastagens constituídas por misturas de leguminosas e gramíneas, contribui para a redução da necessidade de fornecimento de suplementação alimentar para a produção animal. No entanto, apesar dos avanços no entendimento da importância de uma maior diversidade de espécies para a sustentabilidade dos ecossistemas, é grande a necessidade de estudos com sistemas integrados de produção agricultura-pecuária, particularmente na região dos Campos Gerais, no Estado do Paraná.

O objetivo deste trabalho foi avaliar a viabilidade da recria de novilhas leiteiras em pastagens de inverno puras ou consorciadas, sob sistema de ILP.

\section{Material e Métodos}

O experimento foi conduzido em uma área de 17 ha, na unidade de produção de novilhas da Cooperativa Agropecuária Castrolanda, no Município de Castro, PR, entre julho e outubro de 2008 e 2009. Em 2008, o pastoreio ocorreu de 29 de julho a 22 de outubro e, em 2009, de 26 de junho a 5 de outubro. A área experimental está localizada na região fisiográfica denominada Primeiro Planalto Paranaense, situada a $24^{\circ} 47^{\prime} 28^{\prime \prime} \mathrm{S}$ e $50^{\circ} 00^{\prime} 25^{\prime \prime} \mathrm{W}$, e altitude de $1.005 \mathrm{~m}$.
O clima da região, segundo classificação de Köppen, é subtropical úmido do tipo $\mathrm{Cfb}$ (Instituto Agronômico do Paraná, 1994), com verões frescos e invernos com ocorrência de geadas severas e frequentes, sem estação seca definida. A precipitação média anual está entre 1.600 e $1.800 \mathrm{~mm}$.

A área utilizada para instalação do experimento tem sido manejada no sistema de plantio direto há mais de cinco anos, com cultivo de milho ou soja para produção de grãos, no verão, e azevém anual ou aveia-preta para pastoreio animal (novilhas leiteiras) no inverno. O solo predominante na área experimental é classificado como Latossolo Bruno distrófico, com textura argilosa (384 $\mathrm{g} \mathrm{kg}^{-1}$ de areia, $439 \mathrm{~g} \mathrm{~kg}^{-1}$ de argila e $177 \mathrm{~g} \mathrm{~kg}^{-1}$ de silte, na camada de $0-10 \mathrm{~cm}$ de profundidade), fase relevo suave ondulado $(2-4 \%$ de declive médio), segundo levantamento semidetalhado de solos, Município de Castro (2001).

A pastagem consorciada foi semeada em sistema de plantio direto em 15/5/2008, com $50 \mathrm{~kg} \mathrm{ha}^{-1}$ de sementes de azevém anual (Lolium multiflorum Lam.) comum, $80 \mathrm{~kg} \mathrm{ha}^{-1}$ de aveia-preta (Avena strigosa Schreb), $1,7 \mathrm{~kg} \mathrm{ha}^{-1}$ de trevo branco (Trifolium repens L.) e 2,0 $\mathrm{kg} \mathrm{ha}^{-1}$ de trevo vermelho (Trifolium pratense L.). Foram utilizados cerca de $300 \mathrm{~kg} \mathrm{ha}^{-1}$ do formulado NPK 05-25-25, por ocasião da semeadura, $5 \mathrm{~cm}$ ao lado e abaixo da semente, e $150 \mathrm{~kg} \mathrm{ha}^{-1}$ do formulado 22-00-21, como fertilização de cobertura, 36 dias após emergência das plantas. A pastagem de azevém foi semeada em 12/5/2008, com $80 \mathrm{~kg} \mathrm{ha}^{-1}$ de sementes. A adubação de base e de cobertura foi a mesma realizada na pastagem consorciada. Em 2009, a pastagem consorciada foi semeada em 6 de maio, com $60 \mathrm{~kg} \mathrm{ha}^{-1}$ de sementes de azevém anual (comum), $60 \mathrm{~kg} \mathrm{ha}^{-1}$ de aveia-preta, $4 \mathrm{~kg} \mathrm{ha}^{-1}$ de trevo branco e $8 \mathrm{~kg} \mathrm{ha}^{-1}$ de trevo vermelho. A pastagem pura de azevém foi semeada em 5 de maio, com $60 \mathrm{~kg} \mathrm{ha}^{-1}$ de sementes. $\mathrm{Na}$ adubação do segundo ano, para os dois tipos de pastagem, foram utilizados cerca de $380 \mathrm{~kg} \mathrm{ha}^{-1}$ do formulado NPK 03-19-00, por ocasião da semeadura, e $300 \mathrm{~kg} \mathrm{ha}^{-1}$ do formulado 18-00-18, em cobertura, espalhado na área total.

Utilizou-se o delineamento de blocos ao acaso, em arranjo fatorial $2 \times 2$, com duas categorias de animais (leves e pesados) e dois tipos de pastagem (consorciada e pura). Os animais leves apresentavam, em média, $192 \pm 40,9 \mathrm{~kg}$ de peso vivo (PV) e idade média de $9,4 \pm 2,31$ meses, enquanto os animais pesados tinham, 
aproximadamente, $278 \pm 41,2 \mathrm{~kg}$ de PV e idade média de $19,6 \pm 2,47$ meses. Três blocos foram avaliados, cada um contendo os dois tipos de pastagem e as duas categorias de animais. As parcelas dos tratamentos com animais leves ocuparam, em média, 1,2 $\pm 0,42$ ha, e as parcelas com animais pesados, em média, $1,4 \pm 0,59$ ha.

O método de pastoreio foi o contínuo. Cada piquete contou com quatro animais testadores e um número variável de animais reguladores, tendo-se utilizado a técnica "put and take", descrita por Mott \& Lucas (1952), para manter altura de manejo constante de $20 \mathrm{~cm}$ (Carvalho, 2005). Semanalmente, realizouse a medição da altura da pastagem, com auxílio do bastão graduado "sward stick" (Barthram, 1985), em 100 pontos por unidade experimental. Estas avaliações foram realizadas para ajustar a carga animal. Os animais testadores foram novilhas da raça Holandês Preto e Branco (HPB) e mestiças (1/2 sangue) HPB com Jersey. As novilhas foram distribuídas nos piquetes, tendo-se considerado o peso médio dos animais, para manter o peso médio desejado para cada tratamento. Durante o período experimental, os animais receberam água à vontade e sal energético mineralizado na proporção de $100 \mathrm{~g}$ para cada $100 \mathrm{~kg}$ de PV por dia.

Para avaliação da composição química da pastagem, foram realizadas coletas aleatórias a cada 21 dias, durante cinco períodos distintos, com cinco amostras de $0,25 \mathrm{~m}^{2}$ por parcela, cortadas rente ao solo. Após determinação da massa de matéria seca (MS) pela secagem em estufa a $65^{\circ} \mathrm{C}$ até peso constante, estimou-se o teor de proteína bruta (PB), conforme metodologia de Silva (1990), e proporção de fibra em detergente neutro (FDN) e de fibra em detergente ácido (FDA), de acordo com metodologia de Van Soest et al. (1991). Para a estimativa dos nutrientes digestíveis totais (NDT), foram utilizadas as fórmulas descritas por Robinson et al. (2004).

A taxa de acúmulo de MS foi estimada segundo a técnica das gaiolas, com triplo emparelhamento. Foram empregadas três gaiolas por unidade experimental, com dimensões de 50x50 cm. A taxa de acúmulo foi obtida pela diferença entre a MS da amostra colhida dentro da gaiola na data da amostragem (i) e a MS da amostra colhida fora da gaiola na data da amostragem anterior (i - 1), dividida pelo número de dias entre as avaliações (21 dias em média). As amostras foram coletadas com quadrados de ferro, com dimensões de $50 \times 50 \mathrm{~cm}$.

A produção total de MS foi determinada pela soma da massa de forragem inicial com as produções de forragem obtidas a cada intervalo de avaliação (taxa de acúmulo multiplicada pelo número de dias de cada ciclo de pastejo). A oferta de forragem foi calculada com a fórmula $\mathrm{OF}=(\mathrm{MF} / \mathrm{n}+\mathrm{TAC}) 100 / \mathrm{CA}$, em que: OF é a oferta de forragem (\%); MF, a massa de forragem média $\left(\mathrm{kg} \mathrm{ha}^{-1}\right.$ de $\left.\mathrm{MS}\right)=[\mathrm{MF}$ inicial $+\mathrm{MF}$ final/2]; n, o número de dias do ciclo de pastejo; TAC, a taxa de acúmulo de forragem $\left(\mathrm{kg} \mathrm{ha}^{-1}\right.$ por dia de MS); CA, a carga animal média do ciclo de pastejo ( $\mathrm{kg} \mathrm{ha}^{-1}$ de PV).

Os animais foram pesados no início do experimento, na data de entrada nas parcelas, em 29/7/2008 e $26 / 6 / 2009$, e a cada 30 dias até o final do experimento. Todas as pesagens dos animais foram realizadas após jejum prévio de sólidos e líquidos de 12 horas, com balança eletrônica.

A carga animal $\left(\mathrm{kg} \mathrm{ha}^{-1}\right)$ foi obtida pelo somatório dos pesos médios de todos os animais presentes em cada piquete multiplicado pelo número de dias que cada animal permaneceu no piquete, dividido pelo número total de dias de pastejo. $\mathrm{O}$ ganho médio diário dos animais (GMD, kg por animal por dia) foi obtido periodicamente pela diferença entre o peso final e inicial dos animais, dividido pelo número de dias transcorridos entre as pesagens. $\mathrm{O}$ ganho de PV por hectare (Gha, $\mathrm{kg} \mathrm{ha}^{-1}$ ) foi determinado pela multiplicação do GMD dos animais pela lotação por piquete e pelo número de dias que permaneceram em pastejo.

Análises de variância (ANOVA) foram realizadas com os dados de carga animal, GMD, Gha, taxa de acúmulo, massa de forragem, oferta de forragem e composição química da forragem (PB, FDN, FDA e NDT). Os dados foram analisados com o procedimento "General Linear Models" do programa Statgraphics Plus (Manugistics, Rockville, Maryland, EUA), tendose assumido os blocos como efeito aleatório e os demais fatores como efeitos fixos. O efeito período "nested" em cada ano foi introduzido no modelo como um fator repetido no tempo. Quando necessário, antes da ANOVA, os dados foram transformados com a função arco-seno, para satisfazer os testes de normalidade (Dagnelie, 1986). 


\section{Resultados e Discussão}

A análise de variância para PB, FDA, FDN e NDT (Tabela 1) mostra que o período do ano foi o fator de variação mais importante, tendo explicado acima de $70 \%$ da variância total observada em FDA, FDN e NDT. Para PB, o tipo de pastagem (pura ou consorciada) também se destacou como fator de variação. A forragem, independentemente do tipo de pastagem, apresentou PB mais elevada $\left(202,6 \pm 28,88 \mathrm{~g} \mathrm{~kg}^{-1}\right)$ no primeiro período de coleta, em agosto de 2008 ou julho de 2009. Valores de NDT também foram significativamente superiores $\left(678,7 \pm 24,40 \mathrm{~g} \mathrm{~kg}^{-1}\right)$ no primeiro período (Tabela 2). Neste período, a pastagem apresentava-se em pleno desenvolvimento vegetativo. $\mathrm{O}$ ciclo da pastagem terminou em outubro (quinto período), quando os maiores teores de MS, FDA e FDN foram observados, provavelmente em virtude do amadurecimento das plantas (Pontes et al., 2007).

Diferenças significativas, em relação ao ano e ao tipo de pastagem, foram observadas para a variável PB e explicaram, respectivamente, 25 e 16\% da variância total (Tabela 1). Em 2008, observou-se teor médio de PB de $118,5 \pm 55,19 \mathrm{~g} \mathrm{~kg}^{-1}$ e, em 2009, de $167,5 \pm 32,08 \mathrm{~g} \mathrm{~kg}^{-1}$.

A pastagem pura de azevém anual apresentou teor médio de PB de $122,6 \pm 45,26 \mathrm{~g} \mathrm{~kg}^{-1}$, enquanto a pastagem consorciada apresentou teores significativamente mais elevados $\left(163,3 \pm 49,01 \mathrm{~g} \mathrm{~kg}^{-1}\right)$, apesar da baixa proporção de trevos $(6,2 \%)$. Resultados semelhantes foram obtidos por Sleugh et al. (2000), ao verificar teores de $\mathrm{PB}$ em pastagens de gramíneas inferiores ao

Tabela 1. Análises de variância para os teores de proteína bruta, fibra em detergente ácido, fibra em detergente neutro e nutrientes digestíveis totais, com as respectivas proporções (\%) da variância total explicadas (VE).

\begin{tabular}{|c|c|c|c|c|c|c|c|c|c|}
\hline \multirow[t]{2}{*}{$\begin{array}{l}\text { Fonte de } \\
\text { variação }\end{array}$} & \multirow[t]{2}{*}{ GL } & \multicolumn{2}{|c|}{$\begin{array}{l}\text { Proteína } \\
\text { bruta }\end{array}$} & \multicolumn{2}{|c|}{$\begin{array}{c}\text { Fibra em } \\
\text { detergente } \\
\text { ácido } \\
\end{array}$} & \multicolumn{2}{|c|}{$\begin{array}{c}\text { Fibra em } \\
\text { detergente } \\
\text { neutro } \\
\end{array}$} & \multicolumn{2}{|c|}{$\begin{array}{c}\text { Nutrientes } \\
\text { digestíveis } \\
\text { totais } \\
\end{array}$} \\
\hline & & $\mathrm{VE}$ & $\mathrm{p}$ & $\mathrm{VE}$ & $\mathrm{p}$ & VE & $\mathrm{p}$ & $\mathrm{VE}$ & $\mathrm{p}$ \\
\hline Ano (A) & 1 & 25 & $* * *$ & 11 & $* * *$ & 3 & $* * *$ & 11 & $* * *$ \\
\hline Bloco & 2 & 1 & $* *$ & $<1$ & ns & $<1$ & ns & $<1$ & ns \\
\hline Período (B) & 8 & 46 & $* * *$ & 70 & $* * *$ & 79 & $* * *$ & 70 & $* * *$ \\
\hline Peso (C) & 1 & $<1$ & ns & $<1$ & ns & $<1$ & ns & $<1$ & ns \\
\hline Pastagem (D) & 1 & 16 & $* * *$ & 1 & $* * *$ & $<1$ & $*$ & 2 & $* * *$ \\
\hline $\mathrm{AxC}$ & 1 & $<1$ & $* *$ & $<1$ & $* *$ & $<1$ & ns & $<1$ & $* *$ \\
\hline $\mathrm{AxD}$ & 1 & $<1$ & $* *$ & 2 & $* * *$ & $<1$ & $*$ & 2 & $* * *$ \\
\hline $\mathrm{BxD}$ & 4 & - & - & 4 & $* * *$ & 6 & $* * *$ & 4 & $* * *$ \\
\hline
\end{tabular}

observado em misturas de leguminosas e gramíneas. Diversos autores (Zemenchik et al., 2002; Deak et al., 2007) têm relatado que a variação na concentração de $\mathrm{PB}$, em pastagens com misturas de espécies forrageiras, é explicada pela proporção de leguminosas. Portanto, a presença de leguminosas contribuiu para o aumento da qualidade da forragem.

A pastagem pura apresentou teores de FDA e FDN significativamente menores (Tabela 1) que os observados na pastagem consorciada. Os teores médios de FDA foram de $312 \pm 50,9 \mathrm{~g} \mathrm{~kg}^{-1}$ e $325 \pm 50,75 \mathrm{~g} \mathrm{~kg}^{-1}$, respectivamente, na pastagem pura e na pastagem consorciada. Em relação à FDN, a pastagem pura apresentou teores médios de $577 \pm 73,9 \mathrm{~g} \mathrm{~kg}^{-1}$, enquanto a pastagem consorciada apresentou teores médios de $590 \pm 86,3 \mathrm{~g} \mathrm{~kg}^{-1}$. Os valores de NDT também foram significativamente superiores na pastagem pura $\left(604 \pm 58,53 \mathrm{~g} \mathrm{~kg}^{-1}\right)$, em comparação à consorciada $\left(589 \pm 58,38 \mathrm{~g} \mathrm{~kg}^{-1}\right)$.

Quanto à taxa de acúmulo de $\mathrm{MS}$, tanto o fator ano como o fator período de coleta apresentaram efeito significativo (Tabela 3), tendo explicado, respectivamente, 29 e $26 \%$ da variância total. A taxa de acúmulo de MS média em 2008 (74,4 $29,66 \mathrm{~kg} \mathrm{ha}^{-1}$ por dia) foi significativamente superior à taxa de acúmulo em $2009\left(42,4 \pm 19,48 \mathrm{~kg} \mathrm{ha}^{-1}\right.$ por dia). Maiores valores foram observados no terceiro período (74,0 $\pm 31,57 \mathrm{~kg} \mathrm{ha}^{-1}$ por dia), independentemente do tipo de pastagem. Este resultado foi superior ao relatado por Assmann et al. (2004), ao observar valores máximos para a taxa de acúmulo de MS de $57,6 \mathrm{~kg} \mathrm{ha}^{-1}$ por dia em pastagem de azevém e aveia, com ou sem trevo

Tabela 2. Composição química da pastagem (médias de 2008 e 2009, $\mathrm{g} \mathrm{kg}^{-1}$ ), em cinco períodos distintos de coleta (entre julho e outubro) ${ }^{(1)}$

\begin{tabular}{lcccc}
\hline Período $^{(2)}$ & $\begin{array}{c}\text { Proteína } \\
\text { bruta }\end{array}$ & $\begin{array}{c}\text { Fibra em } \\
\text { detergente } \\
\text { ácido }\end{array}$ & $\begin{array}{c}\text { Fibra em } \\
\text { detergente } \\
\text { neutro }\end{array}$ & $\begin{array}{c}\text { Nutrientes } \\
\text { digestíveis } \\
\text { totais }\end{array}$ \\
\hline Primeiro & $202,6 \pm 28,88 \mathrm{a}$ & $247,6 \pm 21,22 \mathrm{~d}$ & $468,6 \pm 48,47 \mathrm{~d}$ & $678,7 \pm 24,40 \mathrm{a}$ \\
Segundo & $141,9 \pm 24,84 \mathrm{~b}$ & $309,8 \pm 29,75 \mathrm{c}$ & $551,3 \pm 41,27 \mathrm{c}$ & $607,3 \pm 34,24 \mathrm{~b}$ \\
Terceiro & $128,9 \pm 39,52 \mathrm{c}$ & $344,6 \pm 30,29 \mathrm{ab}$ & $644,4 \pm 40,97 \mathrm{a}$ & $567,1 \pm 34,85 \mathrm{~cd}$ \\
Quarto & $125,6 \pm 52,00 \mathrm{c}$ & $337,2 \pm 23,39 \mathrm{~b}$ & $608,1 \pm 22,89 \mathrm{~b}$ & $575,7 \pm 26,89 \mathrm{c}$ \\
Quinto & $115,9 \pm 53,34 \mathrm{~d}$ & $354,3 \pm 54,34 \mathrm{a}$ & $648,6 \pm 57,22 \mathrm{a}$ & $556,1 \pm 62,49 \mathrm{~d}$ \\
\hline (1)Médias \pm desvio-padrão & seguidas de letras & iguais, nas colunas, não \\
diferem entre si pelo teste LSD, a 5\% de probabilidade. (2)Primeiro período, \\
29/7/2008 a 12/8/2008 e 26/6/2009 a 8/7/2009; segundo período, 13/8/2008 \\
a 29/8/2008 e 9/7/2009 a 29/7/2009; terceiro período,30/8/2008 a 16/9/2008 \\
e 30/7/2009 a 21/8/2009; quarto período $17 / 9 / 2008$ a 1/10/2008 e 22/8/2009 \\
a 12/9/2009; quinto período, 2/10/2008 a $22 / 10 / 2008$ e $13 / 9 / 2009$ a \\
5/10/2009.
\end{tabular}

Pesq. agropec. bras., Brasília, v.46, n.10, p.1372-1378, out. 2011 
branco. Não foram observadas diferenças significativas na taxa de acúmulo entre os tipos de pastagem e entre os tipos de animais (leves ou pesados). Assmann et al. (2004) relataram que a presença do trevo-branco em pastagens de gramíneas não teve influência na taxa de acúmulo diária de MS.

Em relação à massa de forragem, o fator ano e o período de coleta explicaram, respectivamente, 60 e $15 \%$ da variância total (Tabela 3). Para a oferta de forragem, esses fatores também apresentaram efeito significativo, tendo explicado, respectivamente, 58 e $10 \%$ da variância total. A produção de MS de forragem em 2008 foi, em média, de 3.495,4 $\pm 61,80 \mathrm{~kg} \mathrm{ha}^{-1}$, significativamente superior à MS de forragem em 2009 (1.853,8 $\left.\pm 61,80 \mathrm{~kg} \mathrm{ha}^{-1}\right)$ (Figura 1). Em 2008, a maior massa de forragem foi explicada pela maior taxa de acúmulo de MS verificada $\left(74,4 \pm 29,66 \mathrm{~kg} \mathrm{ha}^{-1}\right.$ por dia) e pela estratégia de manejo adotada. Em 2009, foi utilizada maior carga animal $\left(1.151,1 \pm 46,75 \mathrm{~kg} \mathrm{ha}^{-1}\right)$, em comparação à $2008\left(910,0 \pm 46,75 \mathrm{~kg} \mathrm{ha}^{-1}\right)$. A utilização de maior carga animal média em 2009 mostrou-se mais eficaz, pois proporcionou maior GMD $(0,90 \pm 0,032 \mathrm{~kg}$ por dia por animal) do que em 2008 $\left(0,81 \pm 0,032 \mathrm{~kg}\right.$ por dia), com Gha de $3,10 \pm 0,163 \mathrm{~kg} \mathrm{ha}^{-1}$ por dia, em 2008 , e $3,43 \pm 0,163 \mathrm{~kg} \mathrm{ha}^{-1}$ por dia em 2009. Apesar de a análise de variância não ter mostrado diferença significativa para GMD e Gha quanto ao efeito do ano, esta diferença pode resultar em ganho econômico importante, sem comprometer a produtividade do sistema ILP. Ganhos provenientes de alterações no manejo são muito relevantes quando

Tabela 3. Análise de variância para taxa de acúmulo, massa de matéria seca de forragem $\left(\mathrm{kg} \mathrm{ha}^{-1}\right)$ e oferta de forragem, com as respectivas proporções (\%) da variância total explicadas (VE).

\begin{tabular}{|c|c|c|c|c|c|c|c|}
\hline \multirow[t]{2}{*}{ Fonte de variação } & \multirow[t]{2}{*}{ GL } & \multicolumn{2}{|c|}{$\begin{array}{l}\text { Taxa de } \\
\text { acúmulo }\end{array}$} & \multicolumn{2}{|c|}{$\begin{array}{l}\text { Massa de } \\
\text { forragem }\end{array}$} & \multicolumn{2}{|c|}{$\begin{array}{l}\text { Oferta de } \\
\text { forragem }\end{array}$} \\
\hline & & $\mathrm{VE}$ & $\mathrm{p}$ & VE & $\mathrm{p}$ & $\mathrm{VE}$ & $\mathrm{p}$ \\
\hline Ano (A) & 1 & 29 & $* * *$ & 60 & $* * *$ & 58 & $* * *$ \\
\hline Bloco & 2 & 2 & $\mathrm{~ns}$ & 5 & $* * *$ & $<1$ & $\mathrm{~ns}$ \\
\hline Período (B) & 6 & 26 & $* * *$ & 15 & $* * *$ & 10 & $* * *$ \\
\hline Peso animal (C) & 1 & $<1$ & ns & $<1$ & $\mathrm{~ns}$ & 5 & $* * *$ \\
\hline Pastagem (D) & 1 & $<1$ & $\mathrm{~ns}$ & 4 & ns & 1 & $\mathrm{~ns}$ \\
\hline $\mathrm{A} \times \mathrm{C}$ & 1 & - & - & 2 & $* *$ & 1 & $*$ \\
\hline $\mathrm{B} \times \mathrm{C}$ & 3 & 3 & $\mathrm{~ns}$ & - & - & - & - \\
\hline$B \times D$ & 6 & - & - & 4 & $* *$ & 4 & $*$ \\
\hline $\mathrm{C} \times \mathrm{D}$ & 1 & - & - & 3 & $* * *$ & - & - \\
\hline
\end{tabular}

${ }^{n}$ Não significativo. ${ }^{*},{ }^{* *} \mathrm{e} * * *$ Significativo pelo teste $\mathrm{F}$, a 5,1 e $0,1 \%$ de probabilidade, respectivamente. se trata de pastagens de alta qualidade, em solos de elevada fertilidade, em sistemas em rotação com lavoura (Carvalho et al., 2010).

A oferta de forragem média em 2008, de $21,9 \pm 0,55 \%$, foi significativamente superior à oferta em $2009(10,3 \pm 0,55 \%)$ (Figura 1). Esses valores estão correlacionados à massa de forragem superior observada em 2008 e à maior carga animal utilizada em 2009. Quanto aos períodos de coleta, o terceiro período - de 17/9/2008 a 1/10/2008, e de 22/8/2009 a 12/9/2009 - apresentou a maior oferta de forragem, de 19,48\% (Figura 1). A maior oferta neste período coincidiu com a curva de acúmulo de MS.

Os fatores ano, peso animal e suas interações apresentaram efeito significativo sobre a carga animal (Tabela 4). Contudo, o tipo de pastagem não teve efeito significativo sobre essa variável, embora alguns autores (Restle et al., 2000; Marchezan et al., 2002) tenham relatado que, em pastagens consorciadas, com misturas de gramíneas-leguminosas, a carga animal é, em geral, mais elevada. A carga animal média foi de $910 \pm 46,75 \mathrm{~kg} \mathrm{ha}^{-1}$ de PV, em 2008, e de $1.151 \pm 46,75 \mathrm{~kg} \mathrm{ha}^{-1} \mathrm{em} 2009$. Valores inferiores foram encontrados por Restle et al. (2000) e Marchezan et al. (2002). Para animais leves, a carga animal foi, em média, de $927 \pm 46,75 \mathrm{~kg} \mathrm{ha}^{-1}$ e, para os pesados, de $1.134 \pm 46,75 \mathrm{~kg} \mathrm{ha}^{-1}$. A variável carga animal sofreu efeito da interação entre os fatores ano x peso animal
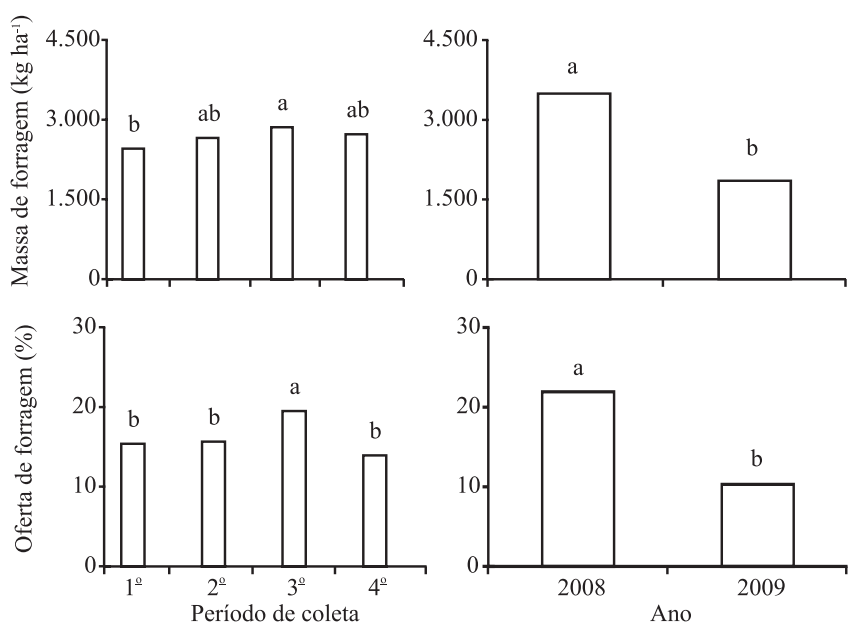

Figura 1. Massa e oferta de forragem em 2008 e 2009, em quatro períodos de coleta: primeiro, $12 / 8$ a 29/8; segundo, 30/8 a 16/9; terceiro, $17 / 9$ a 1/10; e quarto, $2 / 10$ a 22/10 em 2008; e primeiro, 8/7 a 29/7; segundo, 30/7 a 21/8; terceiro, 22/8 a 12/9; quarto, $13 / 9$ a 5/10, em 2009. Médias seguidas de letras iguais não diferem entre si pelo teste $\mathrm{LSD}$, a 5\% de probabilidade. 
(Tabela 1). Maior diferença entre os anos foi observada com animais pesados (diferença de $449 \mathrm{~kg} \mathrm{ha}^{-1}$ contra $34 \mathrm{~kg} \mathrm{ha}^{-1}$ para animais leves).

A análise de variância indica que o fator peso animal teve efeito significativo sobre o Gha. As interações entre os fatores ano $x$ tipo de pastagem e entre tipo de pastagem x peso animal foram significativas para o Gha (Tabela 4). Os animais leves apresentaram Gha superior $\left(3,54 \pm 0,163 \mathrm{~kg} \mathrm{ha}^{-1}\right.$ por dia) aos animais pesados $\left(2,99 \pm 0,163 \mathrm{~kg} \mathrm{ha}^{-1}\right.$ por dia), independentemente do tipo de pastagem. Em 2008, o Gha foi superior em pastagem consorciada, sendo observado o oposto em 2009 (Tabela 5). Os animais leves apresentaram maior Gha em pastagem pura de azevém $\left(3,85 \pm 0,231 \mathrm{~kg} \mathrm{ha}^{-1}\right.$ por dia), enquanto os animais pesados tiveram maior Gha em pastagem consorciada $\left(3,34 \pm 0,231 \mathrm{~kg} \mathrm{ha}^{-1} \mathrm{dia}^{-1}\right)$.

Apenas o fator tipo de pastagem apresentou efeito significativo sobre o GMD (Tabela 4). Animais mantidos em pastagem pura de azevém

Tabela 4. Análise de variância para carga animal, ganho médio diário e ganho por hectare, com as respectivas proporções (\%) da variância total explicadas (VE) .

\begin{tabular}{|c|c|c|c|c|c|c|c|}
\hline \multirow[t]{2}{*}{ Fonte de variação } & \multirow[t]{2}{*}{ GL } & \multicolumn{2}{|c|}{ Carga animal } & \multicolumn{2}{|c|}{$\begin{array}{l}\text { Ganho médio } \\
\text { diário } \\
\end{array}$} & \multicolumn{2}{|c|}{$\begin{array}{c}\text { Ganho por } \\
\text { hectare }\end{array}$} \\
\hline & & VE & $\mathrm{p}$ & VE & $\mathrm{p}$ & VE & $\mathrm{p}$ \\
\hline Ano (A) & 1 & 25 & $* *$ & 10 & ns & 4 & ns \\
\hline Bloco & 2 & 3 & ns & 11 & ns & 13 & ns \\
\hline Peso animal (B) & 1 & 18 & $* *$ & $<1$ & ns & 12 & $*$ \\
\hline Tipo de pastagem (C) & 1 & 3 & ns & 26 & $* *$ & $<1$ & ns \\
\hline$A \times B$ & 1 & 18 & $* *$ & - & - & - & - \\
\hline $\mathrm{A} \times \mathrm{C}$ & 1 & - & - & - & - & 18 & $*$ \\
\hline $\mathrm{B} \times \mathrm{C}$ & 1 & - & - & - & - & 18 & $*$ \\
\hline
\end{tabular}

Tabela 5. Ganho por área $\left(\mathrm{kg} \mathrm{ha}^{-1}\right.$ por dia) obtido em pastagem pura de azevém (Lolium multiflorum) e em pastagem consorciada (Lolium multiflorum, Avena strigosa, Trifolium repens e Trifolium pratense), com animais leves $(192 \pm 40,9 \mathrm{~kg})$ ou animais pesados $(278 \pm 41,2 \mathrm{~kg})$, em 2008 e 2009 .

\begin{tabular}{lcc}
\hline Tratamento & Pastagem consorciada & Pastagem pura \\
\hline 2008 & $3,45 \pm 0,231$ & $2,74 \pm 0,231$ \\
2009 & $3,12 \pm 0,231$ & $3,74 \pm 0,231$ \\
Animais leves & $3,23 \pm 0,231$ & $3,85 \pm 0,231$ \\
Animais pesados & $3,34 \pm 0,231$ & $2,64 \pm 0,231$ \\
\hline
\end{tabular}

apresentaram GMD superior $(0,93 \pm 0,032 \mathrm{~kg}$ por dia por animal) aos dos animais mantidos em pastagem consorciada $(0,79 \pm 0,032 \mathrm{~kg}$ por dia $)$, o que contraria a hipótese de que a maior riqueza de espécies aumenta a produtividade da pastagem. Apesar dos maiores valores de PB observados na pastagem consorciada, em comparação à pastagem pura, estes resultados não se refletiram em maior GMD. A menor proporção de parede celular (FDN e FDA) e a maior proporção de NDT em pastagem pura podem ter contribuído para maior consumo animal e, consequentemente, maior GMD.

Embora os animais mantidos em pastagem pura tenham apresentando GMD superior, os dois tipos de pastagem proporcionaram GMD adequados para ambos os tipos de animais testados (entre 8 e 19 meses de idade). Pirlo et al. (1997) propõem ganho de peso de $0,7 \mathrm{~kg}$ por dia, para novilhas de 3 a 12 meses de idade, e de $0,9 \mathrm{~kg}$ por dia, para novilhas de 12 meses de idade até o parto. Segundo os autores, esses ganhos de peso representam uma alternativa econômica ao produtor e não afetam o desenvolvimento da glândula mamária. O National Research Council (2001) propõe ganho de peso na faixa de 0,8 a $0,9 \mathrm{~kg}$ por dia para novilhas com parto antes dos 24 meses de idade. Restle et al. (2000), ao avaliar bezerras de corte com idade média de 10 meses, em pastagem de aveia-preta e azevém, relataram GMD de 0,615 kg por dia. Resultados similares também foram obtidos por Pilau et al. (2004), ao observar GMD de 0,751 kg por dia, em pastagem de aveia-preta e azevém, sem suplementação. Esses mesmos autores obtiveram GMD de 0,936 kg por dia em animais que receberam suplementação na proporção de 1,5\% do PV, semelhante aos resultados observados neste trabalho, sem suplementação.

\section{Conclusões}

1. Pastagens puras de azevém possibilitam maior ganho médio diário de novilhas em recria do que pastagens de azevém anual consorciadas com aveiapreta, trevo branco e trevo vermelho.

2. O desempenho por unidade de área depende da categoria animal, sendo que novilhas leves têm melhor desempenho em pastagens puras de azevém, enquanto novilhas pesadas têm melhor desempenho em pastagens consorciadas. 


\section{Referências}

ASSMANN, A.L.; PELISSARI, A.; MORAES, A. de; ASSMANN, T.S.; OLIVEIRA, E.B. de; SANDINI, I. Produção de gado de corte e acúmulo de matéria seca em sistema de integração lavoura-pecuária em presença e ausência de trevo branco e nitrogênio. Revista Brasileira de Zootecnia, v.33, p.37-44, 2004.

BALBINOT JUNIOR, A.A.; MORAES, A. de; VEIGA, M. da; PELISSARI, A.; DIECKOW, J. Integração lavoura-pecuária: intensificação de uso de áreas agrícolas. Ciência Rural, v.39, p.1925-1933, 2009.

BARTHRAM, G.T. Experimental techniques: the HFRO sward stick. In: BIENNIAL REPORT OF THE HILL FARMING, 1984-1985, Penicuik. Proceedings. Penicuik: Hill Farming Research Organization, 1985. p.29-30.

CARVALHO, P.C. de F. O Manejo da pastagem como gerador de ambientes pastoris adequados à produção animal. In: SIMPÓSIO SOBRE MANEJO DA PASTAGEM, 22., 2005, Piracicaba. Teoria e prática da produção animal em pastagens: anais. Piracicaba: FEALQ, 2005. p.7-32.

CARVALHO, P.C. de F.; ANGHINONI, I.; MORAES, A. de; SOUZA, E.D. de; SULC, R.M.; LANG, C.R.; FLORES, J.P.C.; LOPES, M.L.T.; SILVA, J.L.S. da; CONTE, O.; WESP, C.L.; LEVIEN, R.; FONTANELI, R.; BAYER, C. Managing grazing animals to achieve nutrient cycling and soil improvement in no-till integrated systems. Nutrient Cycling in Agroecosystems, v.88, p.259-273, 2010.

DAGNELIE, P. Théorie et méthodes statistiques. 2 ed. Gembloux: Les Presses Agronomiques, 1986. v.2, 464p.

DEAK, A.; HALL, M.H.; SANDERSON, M.A.; ARCHIBALD, D.D. Production and nutritive value of grazed simple and complex forage mixtures. Agronomy Journal, v.99, p.814-821, 2007.

GABLER, M.T.; TOZER, P.R.; HEINRICHS, A.J. Development of a cost analysis spreadsheet for calculating the costs to raise a replacement dairy heifer. Journal of Dairy Science, v.83, p.1104-1109, 2000

HEINRICHS, A.J. Raising dairy replacements to meet the needs of the $21^{\text {st }}$ century. Journal of Dairy Science, v.76, p.3179-3187, 1993.

INSTITUTO AGRONÔMICO DO PARANÁ. Cartas climáticas do Estado do Paraná 1994. Londrina: IAPAR, 1994. 49p. (IAPAR. Documentos, 18).

LEVANTAMENTO semidetalhado de solos, município de Castro: relatório interno. Londrina: Embrapa Solos, 2001. 86p.

MARCHEZAN, E.; VIZZOTTO, V.R.; ROCHA, M.G. da; MOOJEN, E.L.; SILVA, J.H.S. da. Produção animal em várzea sistematizada cultivada com forrageiras de estação fria submetidas a diferentes níveis de adubação. Ciência Rural, v.32, p.303-308, 2002.

MORAES, A.; PELISSARI, A.; ALVES, S.J.; CARVALHO, P.C. de F.; CASSOL, L.C. Integração lavoura-pecuária no sul do Brasil.
In: ENCONTRO DE INTEGRAÇÃO LAVOURA-PECUÁRIA NO SUL DO BRASIL, 1., 2002, Pato Branco. Anais. Pato Branco: CEFET, 2002. p.3-42.

MOTT, G.O.; LUCAS, H.L. The design, conduct and interpretation of grazing trials on cultivated and improved pastures. In: INTERNATIONAL GRASSLAND CONGRESS, 6., 1952, State College. Proceedings. State College: Pennsylvania State College, 1952. p.1380-1385.

NATIONAL RESEARCH COUNCIL. Nutrient requirements of dairy cattle. $7^{\text {th }}$ ed. rev. Washington: National Academy Press, 2001.

PILAU, A.; ROCHA, M.G. da; RESTLE, J.; ESTIVALET, R.; NEVES, F.P.; QUADROS, B.P. de. Recria de novilhas de corte com diferentes níveis de suplementação energética em pastagem de aveia preta e azevém. Revista Brasileira de Zootecnia, v.33, p.2104-2113, 2004.

PIRLO, G.; CAPELLETTI, M.; MARCHETTO, G. Effects of energy and protein allowances in the diets of prepubertal heifers on growth and milk production. Journal of Dairy Science, v.80, p.730-739, 1997.

PONTES, L.S.; CARRERE, P.; ANDUEZA, D.; LOUAULT, F.; SOUSSANA, J.F. Seasonal productivity and nutritive value of temperate grasses found in semi-natural pastures in Europe: responses to cutting frequency and N supply. Grass and Forage Science, v.62, p.485-496, 2007.

RESTLE, J.; ROSO, C.; SOARES, A.B.; LUPATINI. G.C.; ALVES FILHO, D.C.; BRONDANI, I.L. Produtividade animal e retorno econômico em pastagem de aveia preta mais azevém adubada com fontes de nitrogênio em cobertura. Revista Brasileira de Zootecnia, v.29, p.357-364, 2000.

ROBINSON, P.H.; GIVENS, D.I.; GETACHEW, G. Evaluation of NRC, UC Davis and ADAS approaches to estimate the metabolizable energy values of feeds equations utilizing chemical assays and in vitro determinations. Animal Feed Science and Technology, v.114, p.75-90, 2004.

SILVA, D.J. Análise de alimentos: métodos químicos e biológicos. 2.ed. Viçosa: UFV, 1990. 165p.

SLEUGH, B.; MOORE, K.J.; GEORGE, J.R.; BRUMMER, E.C. Binary legume-grass mixtures improve forage yield, quality, and seasonal distribution. Agronomy Journal, v.92, p.24-29, 2000.

SMITH, R.G.; GROSS, K.L.; ROBERTSON, G.P. Effects of crop diversity on agroecosystem function: crop yield response. Ecosystems, v.11, p.355-366, 2008.

VAN SOEST, P.J.; ROBERTSON, J.B.; LEWIS, B.A. Methods for dietary fiber, neutral detergent fiber, and nonstarch polysaccharides in relation to animal nutrition. Journal of Dairy Science, v.74, p.3583-3597, 1991.

ZEMENCHIK, R.A.; ALBRECHT, K.A.; SHAVER, R.D. Improved nutritive value of kura, clover - and birdsfoot trefoil - grass mixtures compared with grass monocultures. Agronomy Journal, v.94, p.1131-1138, 2002.

Recebido em 31 de julho de 2010 e aprovado em 1 de agosto de 2011 